\title{
Transient Stability Test Systems for Direct Stability Methods
}

V. Vittal

D Martin

R Chu

J Fish

Poflowithis and additional works at: https://engagedscholarship.csuohio.edu/enece_facpub

Part of the Power and Energy Commons

Beanelxteragefesedditibirahauthdrenefit you? Let us know!

Publisher's Statement

(C) 1992 IEEE. Personal use of this material is permitted. Permission from IEEE must be obtained for all other uses, in any current or future media, including reprinting/republishing this material for advertising or promotional purposes, creating new collective works, for resale or redistribution to servers or lists, or reuse of any copyrighted component of this work in other works.

\section{Original Citation}

Transient stability test systems for direct stability methods. (February 01, 1992). IEEE Transactions on Power Systems, 7, 1, 37-43.

Repository Citation

Vittal, V.; Martin, D; Chu, R; Fish, J; Giri, J C.; Tang, C K.; Villaseca, F. Eugenio; and Farmer, R G., "Transient Stability Test Systems for Direct Stability Methods" (1992). Electrical Engineering \& Computer Science Faculty Publications. 82.

https://engagedscholarship.csuohio.edu/enece_facpub/82

This Article is brought to you for free and open access by the Electrical Engineering \& Computer Science Department at EngagedScholarship@CSU. It has been accepted for inclusion in Electrical Engineering \& Computer Science Faculty Publications by an authorized administrator of EngagedScholarship@CSU. For more information, please contact library.es@csuohio.edu. 
Authors

V. Vittal, D Martin, R Chu, J Fish, J C. Giri, C K. Tang, F. Eugenio Villaseca, and R G. Farmer

This article is available at EngagedScholarship@CSU: https://engagedscholarship.csuohio.edu/enece_facpub/82 


\title{
TRANSIENT STABLITY TEST SYSTEMS FOR DIRECT STABILITY METHODS
}

\section{IEEE COMMITTEE REPORT \\ PREPARED BY THE IEEE STABUITY TEST SYSTEMS TASK FORCE OF THE DYNAMIC SYSTEM PERFORMANCE SUBCOMMITTEE}

\author{
Chairman: V. Vittal
}

\section{ABSTRACT}

The aim of this paper is to present a standard set of power system data with benchmark results against which direct stabillty techniques to assess transient stability could be compared and tested.

The test systems have been selected to display a wide range of dynamic characteristics to provide a robust test of the efficacy and accuracy of the various analytical techniques to analyze transient stability. Transient stability test system data and benchmark results obtained from two commercially avallable time domain stability analysis packages are presented in this paper.

\section{INTRODUCTION}

Modern day power systems exhibit a wide range of complex dynamic behavior. Analysis of such phenomena requires the development of new analytical tools and a variety of applications of conventional time domain simulations. In order to determine the efficacy of the different techniques, they need to be compared using a common system with available benchmark results.

In recent years, several analytical approaches dealing with direct methods for transient stability assessment have been proposed. In some cases, the approaches have been applied to small sample test systems which are not very realistic. Furthermore, in order to provide a relative comparison of the various proposed techniques, there is a need for testing these methods on a realistic system with benchmark results obtained from conventional time domain analysis. This paper addresses such a need. It provides system data for two realistic test systems and provides benchmark transient stablity results using two different commercially available time simulation packages. The packages used are the EPRIExtended Transient/Mid-Term Stability Program (ETMSP) and PTI-Power System Simulation/E Program (PSS/E).

The two systems have been carefully chosen to display a wide range of dynamic characteristics: i) operating conditions are specifed for which these systems display a plant mode of instability where the plant close to the disturbance loses synchronism with the rest of the system; ii) a complex mode of instability where a number of plants are electrically close to each other along a river, and a disturbance close to these plants results in all of them being severely disturbed; iil) an inter-area mode of instability where an entire area separates from another area following a disturbance. This wide range of dynamic response is specifically intended to provide a robust test of the efficacy and accuracy of the various analytical techniques. The benchmark testing has been conducted using three phase faults. Two different kinds of stability limits are provided: i) plant generation limits, and ii) critical clearing time. These limits are obtained using i) the classical power system model, and ii) the two axis machine model with exciters. In all the benchmark tests, the loads are represented as constant impedances.

\section{TEST SYSTEMS}

Two test systems are used to provide the benchmark results: a 17-generator, 162-bus equivalent of the network of the State of lowa, and a 50-generator, 145-bus system.

\section{7-Generator System}

Figure 1 shows the major $345 \mathrm{kV}$ lines in the 17 -generator system. The system has several generating plants along the banks of the Missouri River. These are shown in the left hand side of Figure 1. The electrical proximity of these plants results in a very complex and interesting dynamic behavior of the system. For a three phase fault close to these plants, a large number of plants are severely disturbed resulting in a complex mode of disturbance.

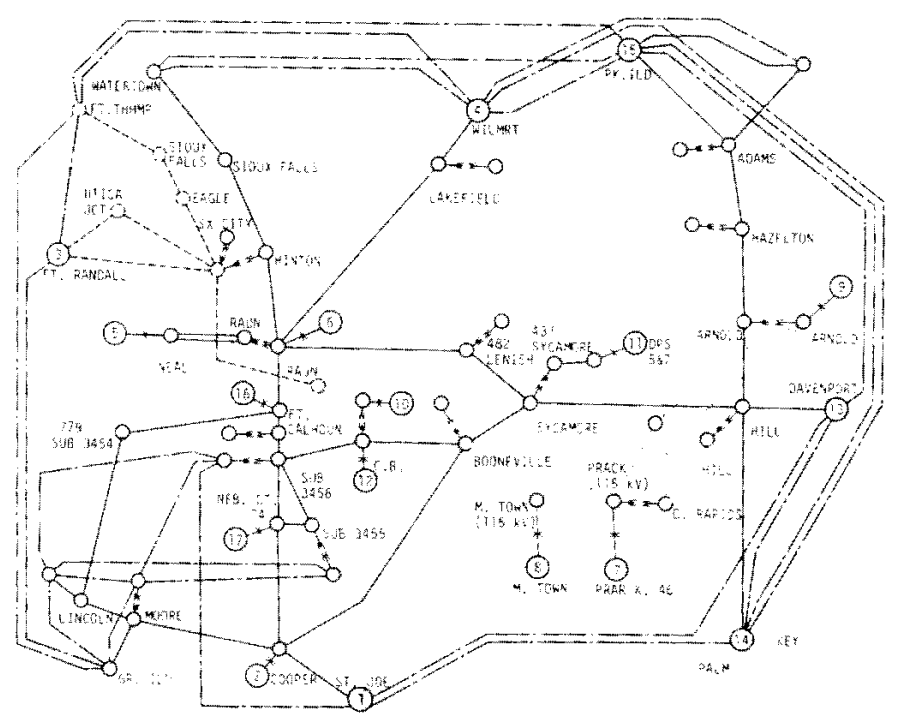

Fig. 1. 17-generator test system: major high voltage lines

Only the classical model data is provided for this system. The machine data is given in Table 1 on a 100 MVA base. The network data is provided in IEEE COMMON FORMAT for power flow exchange [1]. See Section IV for information to obtain the network data on a magnetic diskette. 
Table 1. 17-Generator System Machine Data

\begin{tabular}{|c|r|r|}
\hline $\begin{array}{c}\text { Power Flow } \\
\text { Bus Number }\end{array}$ & \multicolumn{2}{|c|}{ Generator Parameters } \\
\cline { 2 - 3 } & H (s) & $\mathbf{X}_{\mathbf{d}}$ (pu) \\
\hline & 100.00 & 0.004 \\
6 & 34.56 & 0.0437 \\
15 & 80.00 & 0.0100 \\
27 & 80.00 & 0.0500 \\
73 & 16.79 & 0.0507 \\
76 & 32.49 & 0.0206 \\
99 & 6.65 & 0.1131 \\
101 & 2.66 & 0.3115 \\
108 & 29.60 & 0.0535 \\
114 & 5.00 & 0.1770 \\
118 & 11.31 & 0.1049 \\
121 & 19.79 & 0.0297 \\
124 & 200.00 & 0.0020 \\
125 & 200.00 & 0.0020 \\
126 & 100.00 & 0.0040 \\
130 & 28.60 & 0.0559 \\
131 & 20.66 & 0.0544 \\
\hline
\end{tabular}

- On 100 MVA Base.

\section{0-Generator System}

The 50-generator system demonstrates a wide range of dynamic characteristics at different loading levels. For the base case loading level provided in the network data, a three phase fault results in a simple plant mode of instability, where the plant close to the disturbance loses synchronism with the rest of the system. Shifting the generation at two generators and subjecting the system to the identical disturbance as in the plant mode case, results in an inter-area mode of separation where a large area separates from the rest of the system.

Benchmark cases are provided for: 1) the classical model representation, and i1) for six machines represented by the two-axis model and equipped with Type AC-4 [2] exciters. Table 2 provides the machine data for the 50-generator system on a $100 \mathrm{MVA}$ base. The six generators with the two-axis representation are placed at the top of the table. Table 3 provides the Type AC-4 exciter data for these six generators.

Table 2. 50-Generator System Machine Data

\begin{tabular}{|c|c|c|c|c|c|c|c|c|c|c|}
\hline \multirow{2}{*}{$\begin{array}{l}\text { Power } \\
\text { Flow } \\
\text { Bus } \\
\text { Number }\end{array}$} & \multicolumn{10}{|c|}{ Generator Parameters" } \\
\hline & $\mathbf{H}(\mathbf{s})$ & $\mathbf{x}_{\mathbf{d}}^{\prime}(\mathbf{p u})$ & $x_{q}^{\prime}(p u)$ & $x_{d}(p a)$ & $\mathrm{x}_{\mathbf{q}}(\mathbf{p u})$ & $\mathbf{x}_{\mathbf{1}}(\mathbf{p u})$ & $s(1,0)$ & $S(1.2)$ & $T_{\text {to }}(s)$ & $r_{\mathrm{do}}^{*}(s)$ \\
\hline 93 & 115,0366 & 0.024 & 0.03655 & 0.09842 & 0.09673 & 0.01237 & 0.0654 & 0.5743 & 8.50 & 1.24 \\
\hline 104 & 73.8528 & 0.0122 & 0.0144 & 0.1016 & 0.0982 & 0.0081 & 0.2100 & 0.5500 & 10.00 & 1.50 \\
\hline 105 & 84.3915 & 0.0208 & 0.03149 & 0.1144 & 0.1092 & 0.01102 & 0.1300 & 0.4096 & 6.61 & 1.50 \\
\hline 106 & 56.261 & 0.03118 & 0.0472 & 0.17165 & 0.16377 & 0.01653 & 0.1300 & 0.4096 & 6.61 & 1.50 \\
\hline 110 & 115.05 & 0.024 & 0.03655 & 0.09842 & 0.09673 & 0.01237 & 0.0654 & 0.5743 & 8.50 & 1.24 \\
\hline 111 & 73.8528 & 0.0122 & 0.0144 & 0.1016 & 0.0982 & 0.0081 & 0.2100 & 0.5500 & 10.00 & 1.50 \\
\hline 60 & 1.41 & 0.4769 & & & & & & & & \\
\hline 67 & 52.1796 & 0.0213 & & & & & & & & \\
\hline 79 & 6.65 & 0.1292 & & & & & & & & \\
\hline 80 & 1.2857 & 0.6648 & & & & & & & & \\
\hline 82 & 2.115 & 0.5291 & & & & & & & & \\
\hline 89 & 20.5602 & 0.0585 & & & & & & & & \\
\hline 90 & 0.7628 & 1.600 & & & & & & & & \\
\hline 91 & 1.6848 & 0.3718 & & & & & & & & \\
\hline 94 & 17.3424 & 0.0839 & & & & & & & & \\
\hline 95 & 5.4662 & 0.1619 & & & & & & & & \\
\hline 96 & 2.1216 & 0.4824 & & & & & & & & \\
\hline 97 & 5.4912 & 0.2125 & & & & & & & & \\
\hline 98 & 13.96 & 0.0795 & & & & & & & & \\
\hline 99 & 17.108 & 0.1146 & & & & & & & & \\
\hline 100 & 7.56 & 0.1386 & & & & & & & & \\
\hline 101 & 12.2844 & 0,0924 & & & & & & & & \\
\hline 102 & 78.4366 & 0.0135 & & & & & & & & \\
\hline 103 & 8.16 & 0.1063 & & & & & & & & \\
\hline 108 & 30.432 & 0.0248 & & & & & & & & \\
\hline 109 & 2.6622 & 0.2029 & & & & & & & & \\
\hline 112 & 12.2844 & 0.0924 & & & & & & & & \\
\hline 115 & 97.33 & 0.0024 & & & & & & & & \\
\hline 116 & 105.50 & 0.0022 & & & & & & & & \\
\hline 117 & 102.16 & 0.0017 & & & & & & & & \\
\hline 118 & 162.74 & 0.0014 & & & & & & & & \\
\hline 119 & 348.22 & 0.0002 & & & & & & & & \\
\hline 121 & 116.54 & 0.0017 & & & & & & & & \\
\hline 122 & 39.24 & 0.0089 & & & & & & & & \\
\hline 124 & 116.86 & 0.0017 & & & & & & & & \\
\hline 128 & 503.87 & 0.0001 & & & & & & & & \\
\hline 130 & 230.90 & 0.0010 & & & & & & & & \\
\hline 131 & 1101.72 & 0.0001 & & & & & & & & \\
\hline 132 & 120.35 & 0.0016 & & & & & & & & \\
\hline 134 & 802.12 & 0.0003 & & & & & & & & \\
\hline 135 & 232.63 & 0.0008 & & & & & & & & \\
\hline 136 & 2018.17 & 0.0001 & & & & & & & & \\
\hline 137 & 469.32 & 0.0004 & & & & & & & & \\
\hline 139 & 2210.20 & 0.0001 & & & & & & & & \\
\hline 140 & 899.19 & 0.0003 & & & & & & & & \\
\hline 141 & 1474.22 & 0.0001 & & & & & & & & \\
\hline 142 & 950.80 & 0.0003 & & & & & & & & \\
\hline 143 & 204.30 & 0,0023 & & & & & & & & \\
\hline 144 & 443.22 & 0.0004 & & & & & & & & \\
\hline 145 & 518.08 & 0.0018 & & & & & & & & \\
\hline
\end{tabular}


Table 3. 50-Generator System Exciter Data

\begin{tabular}{|c|c|c|c|c|c|c|}
\hline Power Flow & $\mathbf{K}_{\mathrm{A}}$ & $\tau_{\mathrm{A}}$ & $\tau_{\mathrm{C}}$ & $\tau_{\mathrm{B}}$ & $\mathbf{E}_{\mathrm{FD}_{\mathrm{MAx}}}$ & $\mathbf{E}_{\mathrm{FD}_{\text {MiN }}}$ \\
\hline Bus Number & & & & & & \\
\hline 93 & 185.0 & 0.020 & 1 & 1 & 8.89 & -2.00 \\
104 & 253.0 & 0.015 & 1 & 1 & 8.86 & -7.00 \\
105 & 54.63 & 0.468 & 1 & 1 & 7.38 & 0.0 \\
106 & 54.63 & 0.468 & 1 & 1 & 7.38 & 0.0 \\
110 & 185.0 & 0.020 & 1 & 1 & 8.89 & -2.0 \\
111 & 253.0 & 0.015 & 1 & 1 & 8.86 & -7.0 \\
\hline
\end{tabular}

\section{BENCHMARK TESTS}

\section{7-Generator System}

\section{Fault Specification}

Three phase fault at Bus \#75 cleared by opening line between Bus \#75 - Buse \#9.

This benchmark test on the 17-generator system consists of determining the critical clearing time. The specified fault results in a complex mode of disturbance. Seven generators close to the fault are severely disturbed. In the critical case, however, only one generator loses synchronism with respect to the rest of the system as shown in Figure 2 obtained from the ETMSP package. The benchmark results using the ETMSP and PSS/E packages are given in Table 4.

Table 4. 17-Generator System: Critical Clearing Time

\begin{tabular}{|c|c|c|}
\hline $\begin{array}{c}\text { Clearing } \\
\text { Time } \\
\text { In Seconds }\end{array}$ & $\begin{array}{c}\text { Stability } \\
\text { Classification } \\
\text { By ETMSP }\end{array}$ & $\begin{array}{c}\text { Stability } \\
\text { Classification } \\
\text { By PSS/E }\end{array}$ \\
\hline \hline 0.352 & Stable & Stable \\
0.354 & Unstable & Stable \\
0.356 & Unstable & Unstable \\
\hline
\end{tabular}

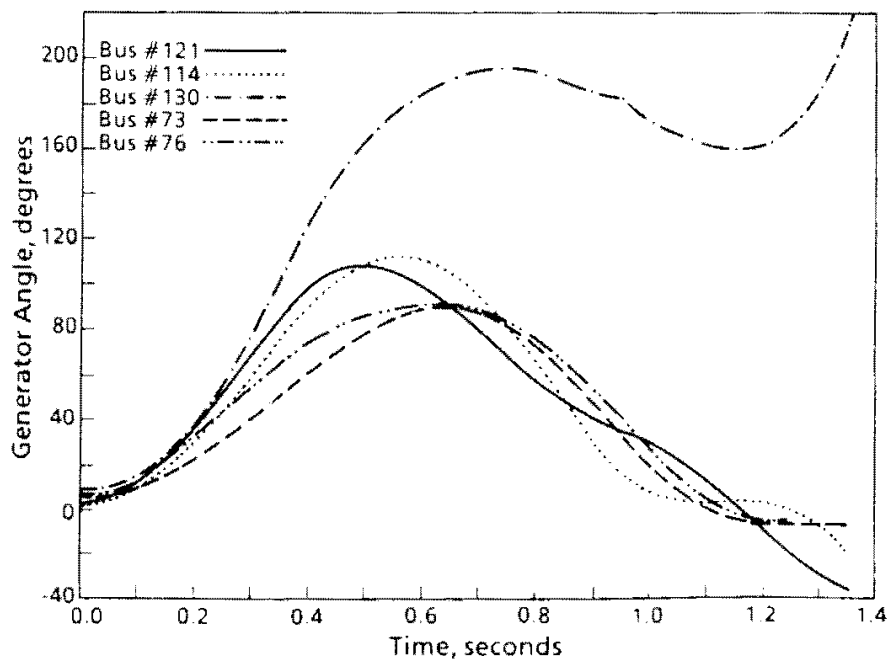

\section{0-Generator System}

\section{Fault Specification}

Three phase fault at Bus \#7 cleared by opening line between Bus $\# 7$ - Bus $\# 6$.

\section{Classical Machine Model}

In this set of tests all the 50-generators are represented by the classical machine model. Two types of stability limits are determined: 1) plant generation limits, and ii) critical clearing time. Two different dynamic characteristics are also studied: 1) plant mode of instability, where the plant closest to the disturbance loses synchronism with the rest of the system, and ii) inter-area mode of instability, where an entire area separates from the rest of the system.

\section{Plant Mode Cases}

Power Flow Features: The base case power flow provided in the diskette represents the operating condition for the plant mode analysis. It is characterized by the generation at Bus \#93 and Bus \#110, being set at $700 \mathrm{MW}$ each.

Plant Generation Limit: In this analysis, the specified fault is always cleared at $0.108 \mathrm{~s}$. The stability limit is determined by changing the generation equally at Bus \#104 and Bus \#111, which are two generators at a plant. The stability limit is calculated in terms of the sum of generation at the above generators. In obtaining new power flow solutions different from the base case provided on the diskette, the generation at Bus \#104 and Bus \#111 is 'changed' in equal steps and the slack Bus \# 145 absorbs all the change.

The plant generation limits obtained using the two packages are given in Table 5.

Table 5. 50-Generator System: Plant Generation Limit Classical Generator Model

Fixed Fault Clearing time $=0.108 \mathrm{~s}$ Plant Mode

\begin{tabular}{|c|c|c|}
\hline $\begin{array}{c}\text { Sum of Generation } \\
\text { At Bus \# 104 and } \\
\text { Bus \#111 }\end{array}$ & $\begin{array}{c}\text { Stability } \\
\text { Classification } \\
\text { By ETMSP }\end{array}$ & $\begin{array}{c}\text { Stability } \\
\text { Classification } \\
\text { By PSS/E }\end{array}$ \\
\hline \hline $4000 \mathrm{MW}$ & Stable & Stable \\
$4010 \mathrm{MW}$ & Unstable & Unstable \\
\hline
\end{tabular}

The rotor angle plots for the generators at Bus \#104 and Bus \#111 with respect to the generator at Bus \#145 using the ETMSP package for the stable and unstable cases are given in Figure 3.

Critical Clearing Time: In this analysis, the base case power flow provided in the diskette is used and the clearing time varied to obtain the critical clearing time. Table 6 shows the results of this analysis obtained using the ETMSP and PSS/E packages. 


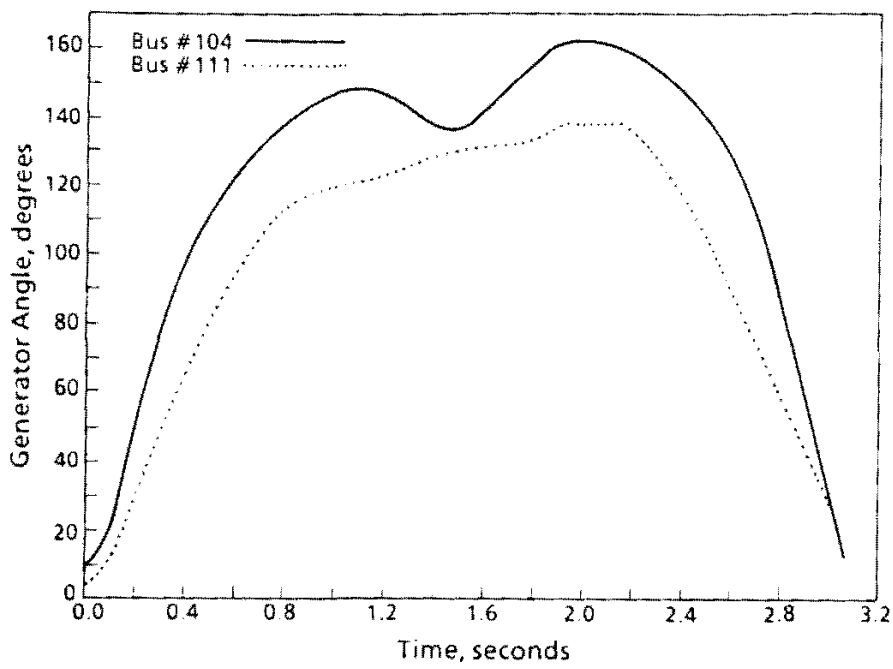

a) Stable case

Fig. 3. 50-generator test system: classical mode, plant mode

Table 6. 50-Generator System: Critical Clearing Time Classical Generator Model

Total Generation at Bus \#104 and Bus $\# 110=4000 \mathrm{MW}$ Plant Mode

\begin{tabular}{|l|c|c|}
\hline $\begin{array}{c}\text { Clearing } \\
\text { Time in } \\
\text { Seconds }\end{array}$ & $\begin{array}{c}\text { Stability } \\
\text { Classification } \\
\text { By ETMSP }\end{array}$ & $\begin{array}{c}\text { Stability } \\
\text { Classification } \\
\text { By PSS/E }\end{array}$ \\
\hline 0.1080 & Stable & Stable \\
0.1085 & Unstable & Unstable \\
\hline
\end{tabular}

Table 7. 50-Generator System: Plant Generation Limit Classical Generator Model

Fixed Fault Clearing Time $=0.108 \mathrm{~s}$

Inter-Area Mode

\begin{tabular}{|c|c|c|}
\hline $\begin{array}{c}\text { Sum of Generation } \\
\text { At Bus \#104 and } \\
\text { Bus \#111 }\end{array}$ & $\begin{array}{c}\text { Stability } \\
\text { Classification } \\
\text { By ETMSP }\end{array}$ & $\begin{array}{c}\text { Stability } \\
\text { Classification } \\
\text { By PSS/E }\end{array}$ \\
\hline $3540 \mathrm{MW}$ & Stable & Stable \\
$3550 \mathrm{MW}$ & Unstable & Unstable \\
\hline
\end{tabular}

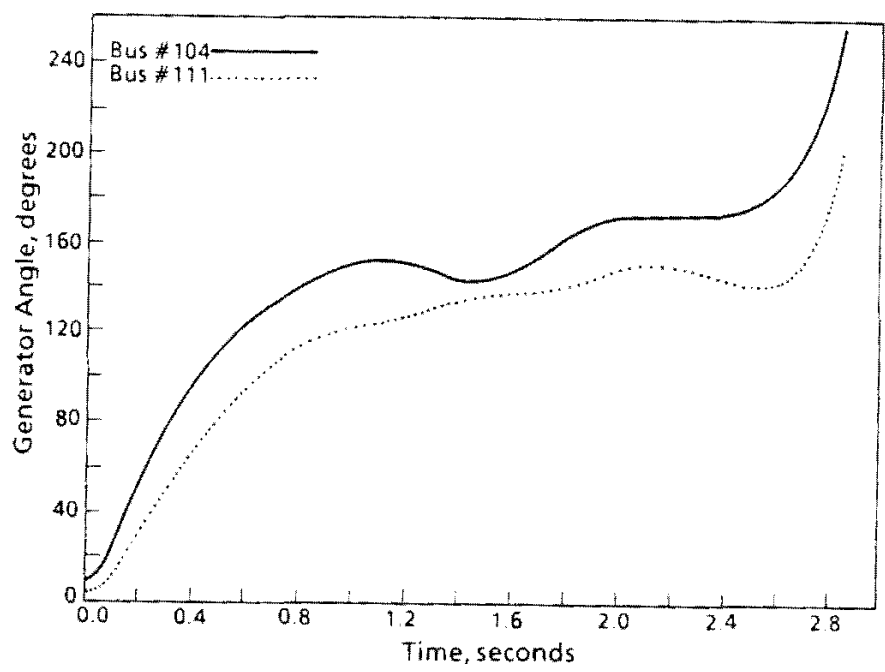

b) Unstable case

\section{INTER-AREA MODE CASE}

Power Flow Features: The base case power flow provided in the diskette has to be altered to obtain the initial conditions for the inter-area mode phenomenon. The power flow is solved by setting the generation at Bus $\# 93$ and Bus $\# 110$ to $1580 \mathrm{MW}$ each and allowing the slack Bus \#145 to account for the change.

Plant Generation Limit: In this analysis the specified fault is always cleared at $0.108 \mathrm{~s}$. The stability lim/t is obtained by changing the generation in equal increments at Bus \#104 and Bus \#111, which are two generators at the same plant. The stability limit is calculated in terms of the sum of the generation at the above generators.

The plant generation limits obtained using the two stability packages are given in Table 7 . In the critically unstable case, 29 generators separate from the rest of the system. The rotor angle plots from the ETMSP package of a few generators with respect to the generator at Bus \#145 is given in Figure 4.

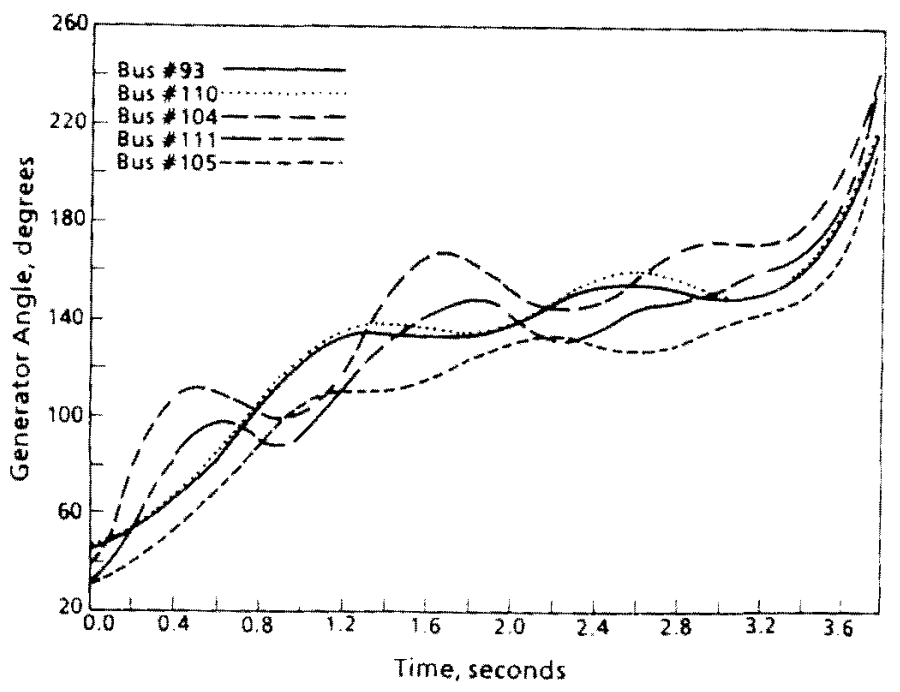

Fig. 4, 50-generator test system: classical model, inter-area mode 


\section{Detalled Machine Model}

In this set of tests, six generators in the 50-generator system are represented by the two-axis model $[3, \mathrm{pg} 138]$, and equipped with Type AC-4 [2] exciters. The detailed machine data is given in Table 2 and the exciter data is given in Table 3. The same fault considered for the classical machine model cases is analyzed. Only the plant mode case is studied, and both plant generation limit and critical clearing time are obtalned.

Plant Generation Limit: The same fault considered in the classical machine model case is analyzed. The stability limit is calculated in terms of the sum of the generation of the generators located at Bus \#104 and Bus \#111. The change cases of the power flow are obtained as described earlier. The results of the test are shown in Table 8.

The difference in results between the two packages is attributed to the differences in the representation of the machine model and the exciter model in the two packages.

Critical Clearing Time: The two critically stable cases from the ETMSP and PSS/E packages are analyzed to obtain the critical clearing time. These results are presented in Table 9.

Table 8. 50-Generator System: Plant Generation Limit

Detalled Generator Model

Fixed Fault Clearing Time $=0.108 \mathrm{~s}$

Plant Mode

\begin{tabular}{|c|c|c|}
\hline $\begin{array}{c}\text { Sum of Generation at } \\
\text { Bus \#104 and Bus \#111 }\end{array}$ & $\begin{array}{c}\text { Stability Classification } \\
\text { By ETMSP }\end{array}$ & $\begin{array}{c}\text { Stability Classification } \\
\text { By PSS/E }\end{array}$ \\
\hline \hline $4250 \mathrm{MW}$ & Stable & Stable \\
$4260 \mathrm{MW}$ & Stable & Unstable \\
$4270 \mathrm{MW}$ & Stable & Unstable \\
$4280 \mathrm{MW}$ & Unstable & Unstable \\
\hline
\end{tabular}

Table 9. 50-Generator System: Critical Clearing Time Detained Generator Model

Plant Mode

\begin{tabular}{|c|c|c|c|}
\hline $\begin{array}{c}\text { ETMSP Results } \\
\text { Output of Bus \# 104 and Bus \#111 } \\
=4270 \mathrm{MW}\end{array}$ & \begin{tabular}{c}
\multicolumn{2}{c|}{ PSS/E Results } \\
Output of Bus \#104 and Bus \#111 \\
$\mathbf{4} 4250 \mathrm{MW}$
\end{tabular} \\
\hline $\begin{array}{c}\text { Clearing } \\
\text { Time (s) }\end{array}$ & $\begin{array}{c}\text { Stability } \\
\text { Classification }\end{array}$ & $\begin{array}{c}\text { Clearing } \\
\text { Time(s) }\end{array}$ & $\begin{array}{c}\text { Stability } \\
\text { Classification }\end{array}$ \\
\hline 0.1090 & Stable & 0.11 & Stable \\
Unstable & 0.12 & Unstable \\
\hline
\end{tabular}




\section{NETWORK DATA}

The network power flow data can be obtained by sending a pre-paid request to the following address:

Iowa State University Computation Center

Reference and Supplies Office

195 Durham Center

Iowa State University

Ames, IA 50011

The data can be requested on either a $3-1 / 2$ "t or $5-1 / 4$ " double density MSDOS formatted diskette.

The diskette is currently priced as follows, any change in pricing will be indicated to the user when the order is placed.

$\begin{array}{lllr}\text { Diskette } & \rightarrow & \text { US } \$ & 12.00 \\ \text { Tax } & \rightarrow & \text { US } \$ & 0.60 \\ \text { US. Shlpping } & \rightarrow & \text { US } \$ & 2.00 \\ \text { Overseas Shipping } & \rightarrow & \text { US } \$ & 7.00\end{array}$

All international orders must be paid for using an international money order in U.S. dollars.

\section{ACKNOWLEDGEMENT}

The task force would like to acknowledge the efforts of Mr. Allen A. Y. T. Chang, Ontario Hydro, in obtaining the benchmark tests using the PSS/E package.
The support of Iowa State University and the efforts of Dr. George Strawn. Director, Iowa State University Computation Center, in providing a mechanism to distribute the data are greatly appreciated.

Members of the Task Force are:

Vijay Vittal (Iowa State Univ.), Chairman

Don Martin (ABB Power Systems)

Ron Chu (Philadelphla Electric Co.)

Jack Fish (Consultant)

J. C. Giri (ESCA Corp.)

James Luint (Pacific Gas \& Electric Co.)

C. K. Tang (Ontario Hydro)

F. Eugenio Villaseca (Cleveland State Univ.)

R. G. Farmer (Arizona Public Service Co.)

\section{REFERENCES}

[1] IEEE Committee Report, "Common Format For Exchange Of Solved Load Flow Data," IEEE Transactions on PAS, pp. 1916-1925. Nov/Dec 1973.

[2] IEEE Committee Report, "Excitation Models for Power System Stabllity Studies," IEEE Transactions on PAS, pp. 494-509, Feb. 1981.

[3] Anderson, P. M., and Fouad, A. A., Power System Control and Stability, Iowa State University Press, 1977. 